\title{
Spatial modelling of benthic cover using remote sensing data in the Aldabra lagoon, western Indian Ocean
}

\author{
S. Hamylton ${ }^{1,2, *}$, T. Spencer ${ }^{2}$, A. B. Hagan ${ }^{2}$ \\ ${ }^{1}$ School of Earth and Environmental Sciences, University of Wollongong, Wollongong, New South Wales 2522, Australia \\ ${ }^{2}$ Cambridge Coastal Research Unit, Department of Geography, University of Cambridge, Downing Place, \\ Cambridge CB2 3EN, UK
}

\begin{abstract}
Spatially explicit ecological modelling was used to predict the distribution of 4 benthic components (live coral, carbonate sand, macroalgae and dead coral) inside the Aldabra lagoon, southern Seychelles, western Indian Ocean. Both classic ordinary least-squares and spatial autoregression techniques were carried out on a field data set of 774 spatially referenced records and 3 satellite remote sensing images to define an empirical relationship between local environmental conditions (water depth and water level variation) and benthic cover. This relationship was then used to generate a synoptic model of the spatial cover and distribution of each benthic component at the landscape (i.e. whole lagoon) scale. Environmental conditions were estimated from satellite remote sensing data (water depth) and using GIS techniques (water level variation). By drawing on species-environment relationships applicable to many lagoons, continuous records of percentage benthic cover were derived for the extensive lagoon $\left(174 \mathrm{~km}^{2}\right)$ at a high measurement level (ratio) for use in conservation and resource management applications. The transition from the ordinary least-squares model to the spatially lagged model was accompanied by a marked growth in predictive power $\left(\mathrm{R}^{2}=0.25\right.$ to 0.79$)$, indicating that neighbourhood context interactions play an important role in determining benthic cover of the Aldabra lagoon.
\end{abstract}

KEY WORDS: Spatial regression · Coral reef · Seychelles $\cdot$ Atoll $\cdot$ Autoregression $\cdot$ Autocorrelation

\section{INTRODUCTION}

The lagoons of coral atolls promote marine primary productivity by enhancing the residence time of oceanic waters (Charpy \& Roubaud-Charpy 1990, Delesalle \& Sournia 1992) and providing calm, stable environments that incorporate depth ranges that are commonly able to support highly diverse benthic communities including mangroves, corals, seagrasses and macroalgae, which provide refugia for coral reef fishes (Leis 1994, Dufour \& HarmelinVivien 1997). An understanding of the benthic composition of atoll lagoon floors and the environmental factors influencing the ecological goods and services they provide is therefore needed to inform conservation practice, particularly the spatial planning of marine reserves (Roberts et al. 2003, Sobel \& Dahlgren 2004, Almany et al. 2009). One of the key challenges to the characterisation of atoll lagoon benthic composition is the paucity of data sets available in these frequently large but often remote environments. Typically, lagoon data sets at the landscape scale (i.e. 10 to $100 \mathrm{~km}^{2}$ ) are characterised by a widespread coverage of abiotic data (e.g. remotely sensed reflectance or bathymetric swath data sets and their derivatives), but only point samples of benthic communities (e.g. phototransects and associated detailed community inventories) 
(Lehmann et al. 2003, Shumchenia \& King 2010, McClanahan \& Karnauskas 2011).

Spatially explicit ecological modelling approaches, in which a clear association is maintained and exploited between quantitative data and the spatial coordinates that locate them, can be used to extrapolate locally sampled records to synoptic landscape-scale (10 to $\left.100 \mathrm{~km}^{2}\right)$ information on biological coverage and distribution. Techniques used include generalized linear regression, generalized additive models, ordinary least-squares regression and boosted regression trees (see Table 1 for a summary of recent studies). Two key advantages of these approaches are that they (1) do not require extensive landscape-scale ecological field surveys, which can be costly and a logistical challenge to achieve, and (2) draw on species-environment relationships to develop benthic cover models in an ecologically meaningful manner. A recent assessment of the effectiveness of surrogates for marine biological diversity used across 264 published studies found that in many instances they provide a robust indication of marine benthic community properties. How- ever, where poor performance has been detected, this appears to be due to differing rates of spatial variation in biological diversity and the surrogates invoked. These difficulties affect tropical reefs to a greater degree than temperate reefs and soft-bottom habitats as a result of their high biological complexity, which is itself strongly correlated to environmental diversity (Mellin et al. 2011).

Environmental controls on coral reef benthic community character include water depth and associated light availability, hydrodynamics, the presence of suspended sediments and the characteristics of sedimentary substrates, water temperature and nutrient availability (Done 2011). These biophysical variables are themselves geographically structured, resulting in distinctive ecological and geomorphological zonation patterns that transcend the reef systems of the Atlantic and Indo-Pacific biogeographic provinces (Blanchon 2011). Spatial autocorrelation captures the extent to which entities that are close together in space tend to be more similar than those further apart (Tobler 1970) by measuring correlation among multiple records of a single variable as a function of

Table 1. Spatially explicit ecological modelling studies on coral reefs and their associated communities

\begin{tabular}{|c|c|}
\hline Spatially explicit modelling study & Source \\
\hline $\begin{array}{l}\text { Generalized regression analysis and spatial prediction models link a coral reef fish } \\
\text { diversity index to depth, fish and habitat characteristics }\end{array}$ & Garza-Pérez et al. (2004) \\
\hline $\begin{array}{l}\text { Generalised additive models link reef bottom features (topographic complexity, } \\
\text { sand-sediment, rock-calcareous pavement, rubble) to water depth and light reflectance }\end{array}$ & Arias-Gonzalez et al. (2011) \\
\hline $\begin{array}{l}\text { Linear regressions and canonical correspondence analysis link ecological variables } \\
\text { (parrotfish, surgeonfish and total herbivore abundance, numbers of fish species and } \\
\text { the percent cover of functional groups) to physical attributes, including distance of site } \\
\text { to the nearest channel, current mean and variability, and current maximum }\end{array}$ & $\begin{array}{l}\text { McClanahan \& Karnauskas } \\
(2011)\end{array}$ \\
\hline $\begin{array}{l}\text { Cellular automaton models simulate coral community dynamics in relation to } \\
\text { recruitment and disturbance }\end{array}$ & $\begin{array}{l}\text { Langmead \& Sheppard } \\
(2004)\end{array}$ \\
\hline $\begin{array}{l}\text { Linear regression links the beta diversity of coral reef communities to water depth } \\
\text { and wave exposure }\end{array}$ & Harborne et al. (2006) \\
\hline $\begin{array}{l}\text { Boosted regression trees and maximum entropy species distribution modelling } \\
\text { predict coral reef fish distribution on the basis of topographic complexity and } \\
\text { geographic location across a reef platform shelf }\end{array}$ & Pittman \& Brown (2011) \\
\hline $\begin{array}{l}\text { A Bayesian meta-analysis of the effectiveness of biological surrogates for predicting } \\
\text { marine biodiversity }\end{array}$ & Mellin et al. (2011) \\
\hline $\begin{array}{l}\text { Monte Carlo simulations and linear regression link benthic rugosity and evenness } \\
\text { to the abundance of reef fishes }\end{array}$ & Purkis et al. (2008) \\
\hline $\begin{array}{l}\text { Boosted regression trees link LiDAR derived topographic complexity to the diversity } \\
\text { and abundance of fish and corals }\end{array}$ & Pittman et al. (2009) \\
\hline $\begin{array}{l}\text { Generalized linear models predicted juvenile fish species richness and abundance } \\
\text { across a range of spatial scales from remotely sensed habitat maps }\end{array}$ & Mellin et al. (2007) \\
\hline $\begin{array}{l}\text { Generalized linear mixed-effects models predicted species richness and } \\
\text { abundance of coral reef fishes from environmental variables including depth, } \\
\text { sea surface temperature, salinity and nutrient concentrations }\end{array}$ & Mellin et al. (2010) \\
\hline
\end{tabular}


relative locational position. In the case of benthic communities, finer scale geographical patterning may be underpinned by spatially structured ecological processes driven through neighbourhood interactions such as disease, competition and community recruitment dynamics (Stevens 2005).

From a statistical standpoint, spatially explicit techniques that incorporate spatial autocorrelation have several advantageous features that make them particularly useful for the development of ecological models of benthic community character. These include: (1) the ability to quantify the extent and patterning of autocorrelation across reef benthic surfaces; (2) the ability to index the nature and degree to which a fundamental assumption of classic (non spatial) statistical techniques is violated, e.g. the independence of observations; (3) the ability to indicate the nature (endogenous versus exogenous) of an observable spatial pattern across a lagoon floor; and (4) the ability to utilise information on neighbouring ecological communities, such as adjacent reef patches, as a surrogate for a missing variable. These advantages have been well recognised and incorporated into terrestrial community ecology studies (Lichstein et al. 2002, Beale et al. 2010, Dray et al. 2012). Despite these advances, spatial autocorrelation is seldom incorporated into ecological modelling studies on coral reef systems, representing a significant methodological gap that, if addressed, has the potential to aid the better understanding of coral reef biodiversity. For example, the one study listed in Table 1 that did incorporate spatial autocorrelation into the modelling procedure found that this doubled the power of the model in terms of explaining species abundance (Mellin et al. 2010).

This study draws on the advantageous characteristics of the spatially explicit approaches outlined above by invoking a method that accounts for the spatial autocorrelation of lagoon benthic communities. Two different regression models are used to predict the spatial distribution of benthic cover types (live coral, carbonate sand, macroalgae and dead coral) inside the large Aldabra lagoon, using the environmental parameters of water depth and water level variation. These parameters play a large role in determining the physical environmental drivers of water renewal time (Andréfouët et al. 2001), hydrological regime (Pages \& Andréfouët 2001), wave stress, tidal currents (Kraines et al. 2001), water exchange and wave pumping (Adjeroud et al. 2001) and bathymetry (Leclerc et al. 1999), which are all known to be important determinants of the distribution of biological communities in coral reef lagoons.
Furthermore, these environmental parameters can be readily derived and robustly characterised from remotely sensed imagery, often with a root mean square error of $<0.3 \mathrm{~m}$ in the case of derived water depths (Stumpf et al. 2003). The first model uses ordinary least-squares regression, whereas the second model introduces a spatially lagged term to account for autocorrelation in the environmental parameters. As far as we are aware, this is the first application of spatially lagged autoregressive modelling to the distribution of atoll lagoon benthos.

Aldabra Atoll is a particularly appropriate site at which to undertake such a modelling exercise. The lagoon covers an area of $174 \mathrm{~km}^{2}$, making it one of the largest enclosed atoll lagoons in the Indian Ocean (Andréfouët et al. 2009). This large size allows for the development of spatial gradients in environmental controls; water depths in the lagoon vary from over $20 \mathrm{~m}$ in the main channels to $<5 \mathrm{~m}$ in the central lagoon and the atoll's east-west orientation under a $\mathrm{SE}$ trade wind regime for much of the year produces clear variations in wave climate regime within the lagoon. Information from this location is also of regional significance because Aldabra Atoll was designated a UNESCO World Heritage Site in 1982 because of its isolated position and largely unexploited natural resources, which have preserved a wealth of both terrestrial and shallow marine biodiversity (Stoddart 1968, Hillary et al. 2002). The Aldabra lagoon therefore provides not only an anthropogenically undisturbed system in which to define biodiversity-environment relationships, but also a benchmark of lagoon benthic biodiversity in a region heavily exploited and impacted by human pressures (e.g. regional islands and coastlines such as northern Madagascar, Comores and East Africa).

\section{MATERIALS AND METHODS}

\section{Study location}

Aldabra Atoll $\left(9^{\circ} 24^{\prime} \mathrm{S}, 46^{\circ} 20^{\prime} \mathrm{E}\right)$ lies $420 \mathrm{~km}$ northwest of Madagascar and $620 \mathrm{~km}$ east of the African continental mainland (Fig. 1). The lagoon accounts for almost half the total atoll area of $365 \mathrm{~km}^{2}$ and is larger than the encircling land area of elevated (average $+4.5 \mathrm{~m}$, maximum $8 \mathrm{~m}$ ) Pleistocene reef limestones $\left(155 \mathrm{~km}^{2}\right.$, including the 2 rocky islands in the lagoon, Ile Esprit in the southwest, and Ile Michel in the east) (Stoddart et al. 1971). The lagoon is drained by: (1) 2 main channels, Grande Passe (between Polymnie and Ile Picard) and Passe Houareau (be- 


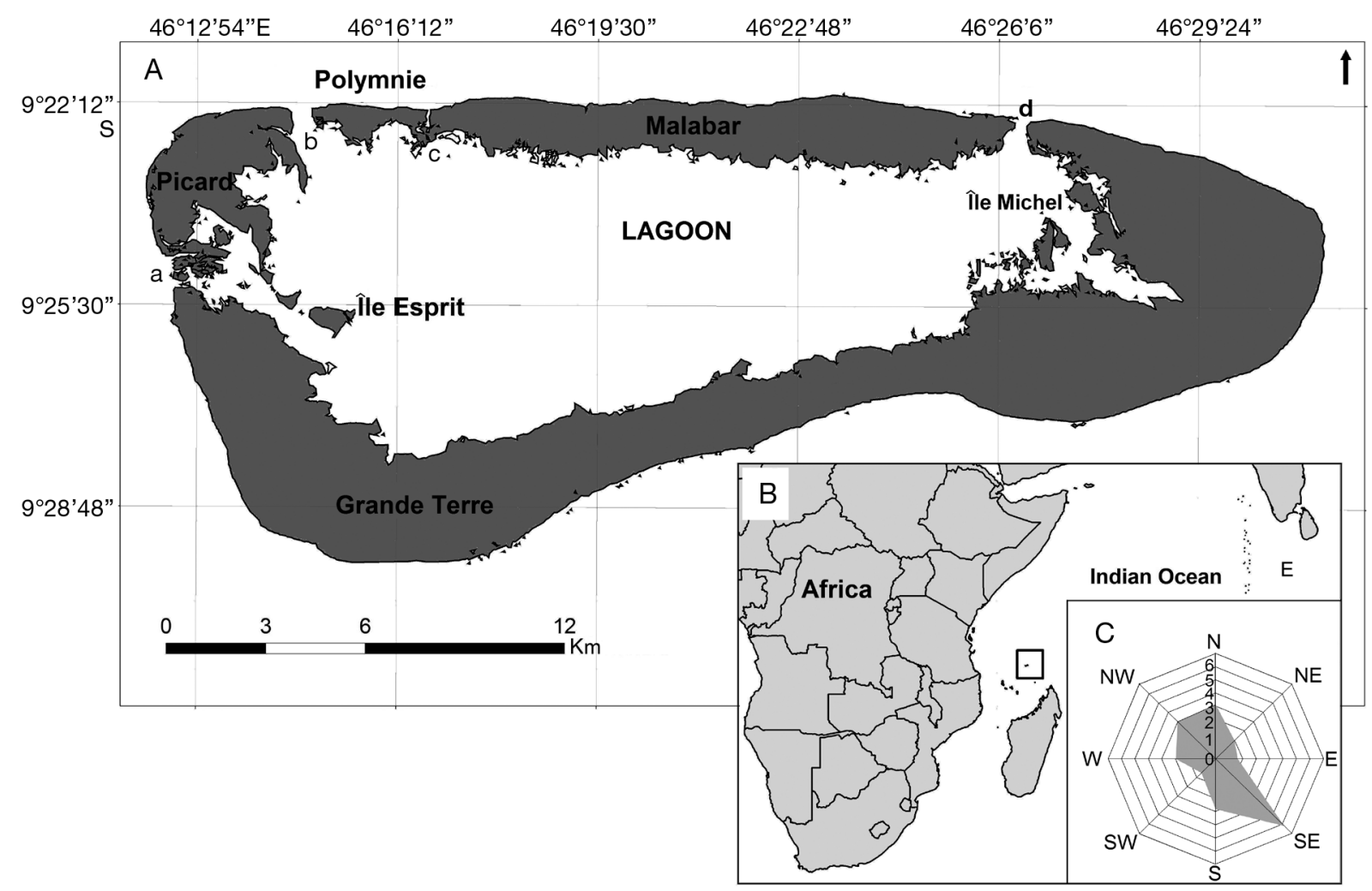

Fig. 1. (A) Aldabra Atoll. Channels are labelled as follows: (a) West Channels, including Passe du Bois; (b) Grande Passe; (c) Passe Gionnet; and (d) Passe Houareau. (B) Location of Aldabra Atoll in the western Indian Ocean. (C) Wind rose, depicting the frequency with which wind blows from the cardinal and subcardinal directions (days per year). Wind data were acquired from the WaveWatch III application (Tolman 2002)

tween Grande Terre and Ile Malabar); (2) a small, deep channel, Passe Gionnnet, between the 2 islands (Polymnie and Ile Malabar) along the north coast; and (3) a series of shallow channels, the West Channels, between Ile Picard and Grande Terre (Fig. 1). Grande Passe, $300 \mathrm{~m}$ wide at its entrance, extends $6 \mathrm{~km}$ into the lagoon in a bifurcating network of nearvertically sided and flat-bottomed channels. These channels maintain depths of up to $30 \mathrm{~m}$ for $3 \mathrm{~km}$ into the lagoon and remain $10 \mathrm{~m}$ deep until near their lagoonal limits. Maximum depths of 15 and $9 \mathrm{~m}$ characterise Pass Houreau and Passe Gionnet, respectively, but only Passe du Bois is deeper than $5 \mathrm{~m}$ in the West Channels (Stoddart 1984).

Lagoon shores are either undercut limestones, the degree of intertidal notching varying with exposure (Taylor 1971), or mangrove-fringed, with mangrove forests (high and low), thickets and fringing belts (Macnae 1971). Lagoonal cliff recession has left numerous remnant 'mushroom' rocks on shore platforms around the lagoon. The lagoon is rock-floored, flat and smooth, quite unlike the karstic topography of many large atoll lagoons (e.g. Shepard 1970, Purdy
1974, Menard 1982) and only thinly veneered (typically $30 \mathrm{~cm}$, maximum thickness of $1 \mathrm{~m}$ ) with sediments (Stoddart et al. 1971). Farrow (1971) identified 3 lagoonal sedimentary environments - sandflats, carbonate mudflats and mangrove mudflats - and Taylor (1978) provided an initial map of lagoon sediments, showing that a large area of the lagoon is sediment-free. The mean spring tidal range of $2.74 \mathrm{~m}$ at Aldabra is high by oceanic atoll standards but reduces rapidly within the lagoon; thus at Pass Houareau, the oceanic tide of over $3 \mathrm{~m}$ is reduced to $1.2 \mathrm{~m}$ within $500 \mathrm{~m}$ of the channel mouth (Farrow \& Brander 1971). At low neap tides much of the lagoon becomes dry, with the rock basement subject to ponding in local bathymetric depressions (Potts \& Whitton 1980).

\section{Model dependent variable: field measurement of benthic cover statistics}

The coverages of different benthic classes (live coral, bare carbonate sand, macroalgae and dead 
coral, see Fig. 3) were sampled from a stationary boat at 486 ground reference locations distributed throughout the lagoon (Fig. 2). Data records consisted of a snapshot (typically $30 \mathrm{~s}$ ), covering an area of $10 \mathrm{~m}^{2}$ of oblique underwater video footage taken from a Seaviewer drop cam 950 mounted on a submarine cable. At each video referencing point (the depths of which ranged across the lagoon from $1 \mathrm{~m}$ to approximately $20 \mathrm{~m}$ ), the tethered underwater video camera was lowered from the boat and held so that it drifted approximately $10 \mathrm{~cm}$ above the lagoon floor. A weight was attached to the base of the video camera so that it dropped rapidly through the water column to minimise drift error. Depth was measured using a HawkEye single beam bathymetric sonar sounder and the geographical position of each footage sample was recorded by differential GPS on the boat (positional accuracy $\pm 0.2 \mathrm{~m}$ ). The rapidity of video camera deployment permitted efficient ground referencing over an extensive area of the lagoon. This would not have been possible using traditional SCUBA diving approaches during the limited (3.5 wk) fieldwork period.

Each $30 \mathrm{~s}$ video footage record was viewed and the proportion of benthic cover (\% cover) was visually estimated for the 4 classes. Percentage cover was chosen in order to standardise between different areas covered during the period of video camera operation because of variations in boat speed and water current. In addition to the video snapshots, 287 photographs were taken using a Nikon D70S in a Nexus underwater housing as additional ground ref- erencing points to assess the accuracy of the models generated. These were assessed for substrate type and cover using the computer programme Coral Point Count (Kohler \& Gill 2006), in which 20 spatially random points were distributed on each photograph. The feature underlying each of the 20 points was identified and the coverage of each of the 4 benthic classes was estimated for each location (Kohler \& Gill 2006).

\section{Model independent variables: water depth and level variation}

Three QuickBird satellite images covering the study area with a spatial resolution of $1 \mathrm{~m}$ were used to derive the water depth of each image pixel (Fig. 2). The images were acquired on 4 and 6 February and 6 March 2001. As a pre-processing step, each image was atmospherically corrected using empirical line methods (Karpouzli \& Malthus 2003).

\section{Water depth model}

A band ratio transformation was applied to the 3 satellite images to derive the water depth of each image pixel. This method established a relationship between the changing ratio of 2 atmospherically corrected water-penetrating waveband pairs at green $(560 \mathrm{~nm})$ and blue $(485 \mathrm{~nm})$ wavelengths and water depth (Stumpf et al. 2003). This was done using 15 readings that were taken in situ and corrected to a common vertical datum of mean sea level. This was determined from the measurement of water level variations over semi-diurnal tidal cycles, using a pressure transducer and Campbell 21X datalogger in Passe du Bois (Fig. 1). Resulting depth estimations were then compared with an additional 188 point water depth measurements recorded in the field, which were also corrected to mean sea level by removal of the tidal signal.

\section{Water level variation model}

Two energy sources were considered for the estimation of water level variation in line with the lagoon circulation models outlined by Wiens (1962): (1) ex-
Fig. 2. Field sampling at Aldabra Atoll, 16 January to 11 February 2009. Black dots depict ground reference points; red outlines illustrate the extent of each satellite image used. From west to east, the 3 images were acquired on 4 and 6 February and 6 March 2001, respectively 
posure to wind-driven waves and (2) tidally driven subsurface currents. Because of the high tidal range at Aldabra, water circulation patterns are tidally driven with secondary wind influence on the water column surface layer, particularly from the southeast, where fetch distances across the lagoon are significant (the lagoon is $35 \mathrm{~km}$ in length along its primary axis (Fig. 1) (Farrow \& Brander 1971, Schott \& McCreary 2001). A first-order model of overall water level variation across the extent of the lagoon, $X_{2}$, was calculated as the product of tidal, $M_{\mathrm{t}}$ and winddriven, $M_{\mathrm{w}}$ circulation (Eq. 1):

$$
X_{2}=M_{t} \sum_{1}^{8} M_{w}
$$

Tidally driven flow, $M_{\mathrm{t}}$, is restricted to the channels linking the lagoon to the open ocean. To derive this term, a simple model of the spatial distribution of flow in relation to these channels was generated on the basis of the distance from each channel opening. Distances further away from channels are less influenced by tidal circulation than those closer to channels, with the influence decreasing in a linear fashion because of friction with distance from channel opening. A linear bottom friction coefficient, $K$, of 0.015 and $0.024 \mathrm{~m} \mathrm{~s}^{-1}$ has been estimated for Passe Houareau and Grande Passe, respectively (Pugh 1979, Pugh \& Rayner 1981). A spatially explicit application of this distribution model was executed in ArcGIS 10 by creating a point surface that defined the centre point of each channel opening at the outer point of the lagoon rim and generating a raster data set across the whole lagoon in which pixel values represented the Euclidean distance from the nearest channel opening. For each pixel, the linear model was applied to calculate subsurface water flow. The higher friction coefficient was applied to those channels where subsurface features such as coral heads and sand megaripples were apparent. The lower coefficient was applied to Grande Passe, where the bottom is subject to tidal scour (Farrow \& Brander 1971).

A GIS-based generic model for estimating relative wave exposure, GREMO, was applied estimate the influence of wind waves, $M_{\mathrm{w}}$ on the basis of fetch lengths summed for 8 cardinal and subcardinal directions and local wind field data (Pepper \& Puotinen 2009). To define fetch lengths across the study area, a land boundary outline was created using the infrared band of the 3 QuickBird images. Areas of high infrared signal were interpreted as land and converted to a vector layer. All land polygons were deleted to produce a data layer in which areas over water had a value of 1 and those over land had a value of 0 . A
$30 \mathrm{~m}$ interval point grid was placed over the study area and the radiating lines extension tool in Arc View10 (Jenness 2006) was used to generate 8 lines, each $20 \mathrm{~km}$ in length, spaced $45^{\circ}$ apart, originating from each grid point (Pepper \& Puotinen 2009). All fetch-limited lines (i.e. those intersecting an overlaid coastline shapefile) were trimmed at the point of intersection with the coastline of the inner atoll rim. Polyline lengths were then summed for each gridpoint and input as fetch distances from each wind direction into the relative wave exposure model. Wind field data were acquired from the WaveWatch III application developed by the National Oceanographic and Atmospheric Administration (for further details, see Tolman 2002). Records of mean monthly wind speed at an elevation of $10 \mathrm{~m}$ were exported for the southern Seychelles cell at $7^{\circ} \mathrm{S}, 52^{\circ} \mathrm{E}$, weighted to account for frequency from each of the cardinal and subcardinal directions and input into the model to reflect cumulative influence of wind direction and wind speed across a 5 yr period (2000 to 2005).

\section{Model construction}

The 2 regression procedures, ordinary least-squares (classic) regression and spatially lagged autoregression, were carried out using the set of 486 data cases in the software GeoDa (Smirnov \& Anselin 2001). Each data case represented a sample location inside the lagoon for which there was a field measure of benthic cover (dependant variable) and associated modelled values for water depth and water level variation (independent variables). The 2 types of regression analysis were carried out in sequence. Firstly, for the 486 ground reference locations, the coefficients of variation $\beta_{0}$ to $\beta_{2}$ were determined and the proportion of variation accounted for by each benthic cover model was measured. Secondly, for a spatially continuous grid of $1 \mathrm{~m}$ interval points across the whole lagoon, a predicted value and residual for each benthic cover type were generated. For the classical regression procedure, cases were input into Eqs. (2) and (3):

$$
\begin{gathered}
Y_{(i)}=\mu_{(i)}+e_{(i)} \quad i=1, \ldots, n \\
\mu_{(i)}=\beta_{0}+\beta_{1} X_{1(i)}+\beta_{2} X_{2(i)}
\end{gathered}
$$

where $n$ is the number of points or areas, $X_{1}$ and $X_{2}$ are the independent variables of water depth and movement, respectively, $e_{(i)}$ is the independent, normally distributed error term, and $\beta_{0}$ and $\beta_{2}$ are coefficients estimated using the model. 
In the second regression model, a spatially lagged autoregressive term was introduced as an independent variable. This approach explicitly drew on the location of each individual case through the construction of a spatial weights matrix $\left(\mathbf{W}_{(i, j)}\right)$ that expressed for each case, those locations that belong to its neighbourhood, such that $w_{(i, j)}=1$ when $i$ and $j$ are neighbours and $w_{(i, j)}=0$ otherwise (Anselin \& Bera 1998). The values of the dependent variable at neighbouring locations were therefore introduced into Eq. (4):

$$
\begin{aligned}
\mu_{(i)}= & \beta_{0}+\beta_{1} X_{1(i)}+\beta_{2} X_{2(i)}+\rho \sum_{j \in N_{(i)}} W_{(i, j)} Y_{(j)}+e_{(i)} \\
& i=1_{1} \ldots, n
\end{aligned}
$$

where $\rho$ is a parameter associated with the interaction effect (Haining 2003).

To estimate the autoregressive terms in the spatial lag model, all cases and the spatial weights matrix were input into a maximum likelihood procedure that generated consistent estimates of $\rho$ and $\beta$. A distinguishing feature of the likelihood for linear regression parameters with a spatial autoregressive component is a Jacobian term of the form $\left|I-\rho \mathbf{W}_{(i, j)}\right|$, an evaluation of which was carried out based on the characteristic polynomial of the spatial weights matrix, $\mathbf{W}_{(i, j)}$, to maximise the likelihood function of this term.

After each regression analysis, the output function was used to predict benthic cover continuously across the lagoon, diagnostics were recorded and the spatial distribution of model residuals was mapped. For the classical regression, diagnostics included the Moran's I statistic for spatial autocorrelation. This statistic measures the tendency for similar values to be located close together in space. Values close to -1 indicate strong negative autocorrelation (a tendency for dissimilar values to be close together), whereas values close to 1 indicate strong positive autocorrelation (a tendency for similar values to be close together), and values close to 0 indicate a lack of association. For the spatial regression, diagnostics consisted of the estimated coefficients and their asymptotic errors, $t$-test and measures of fit. Finally, by way of validation, the predicted proportions of the 4 benthic cover classes were compared with the
287 underwater photographs and the correspondence between the 2 was assessed via a linear regression.

\section{RESULTS}

\section{Field measurement of benthic cover}

Many of the ground reference points visited supported a mixture of benthic cover components (Fig. 3). However, the most prevalent benthic cover class observed in the Aldabra lagoon was macroalgae, which dominated at $64 \%$ of the ground reference points (see Table 2 for average coverage values across the 486 ground reference points).
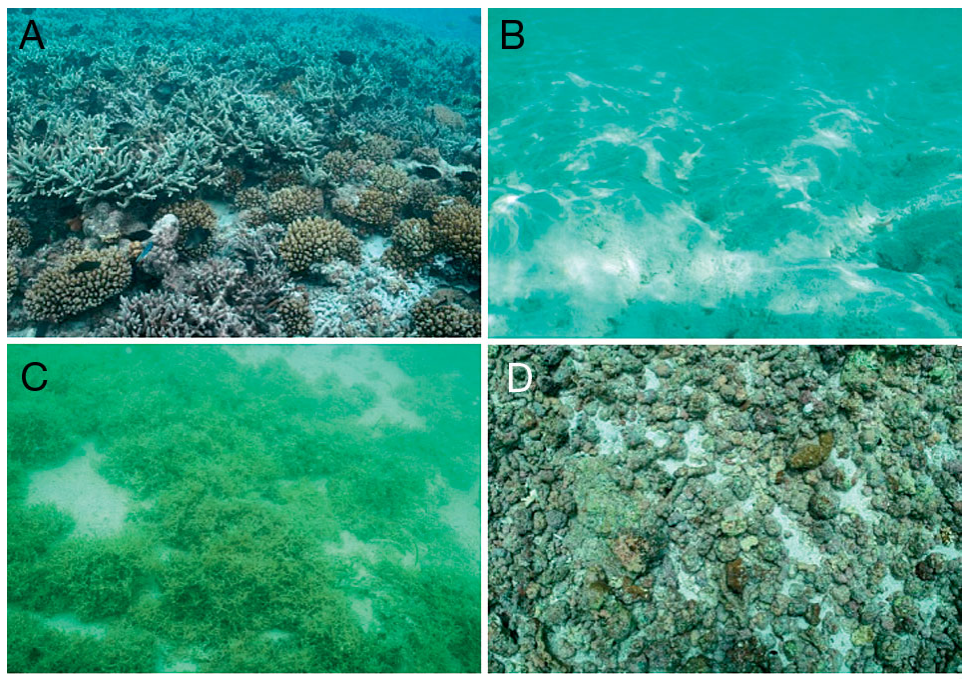

Fig. 3. Benthic cover components modelled inside the Aldabra lagoon: (A) live coral, (B) bare carbonate sand, (C) macroalgae and (D) dead coral. Photos: A. Hagan

Table 2. Ground reference points collected for benthic cover components of the Aldabra lagoon. Coverage statistics have been averaged for all video footage samples within each group and only dominant classes

\begin{tabular}{|c|c|c|c|}
\hline Benthic cover & $\begin{array}{l}\text { No. of } \\
\text { samples }\end{array}$ & $\begin{array}{l}\text { Average } \\
\text { depth (m) }\end{array}$ & $\begin{array}{l}\text { Dominant benthic } \\
\text { cover classes }\end{array}$ \\
\hline Live coral & 67 & 4 & $\begin{array}{l}48 \% \text { live coral } \\
20 \% \text { dead coral } \\
16 \% \text { rubble } \\
16 \% \text { coralline algae }\end{array}$ \\
\hline Bare carbonate sand & 76 & 2 & $\begin{array}{l}74 \% \text { sand } \\
10 \% \text { algae }\end{array}$ \\
\hline Macroalgae & 310 & 1 & $\begin{array}{l}70 \% \text { Hypnea esperi } \\
20 \% \text { Enteromorpha sp. } \\
10 \% \text { Caulerpa spp. }\end{array}$ \\
\hline Dead coral & 33 & 2 & $\begin{array}{l}70 \% \text { rubble } \\
20 \% \text { dead coral }\end{array}$ \\
\hline
\end{tabular}
are reported, which do not sum to $100 \%$ 


\section{Model independent variables: water depth and water level variation}

The water depth model inside the study area predicted depths, relative to mean sea level, that ranged between a minimum value of $0.2 \mathrm{~m}$ above reef patches and a maximum value of $30 \mathrm{~m}$ inside Grande Passe in the northwest of the lagoon (Fig. 4A). These predictions closely approximated the values of 188 validation points measured in situ with a bathymetric sounder and corrected to mean sea level by removal of tidal fluctuations as recorded at Passe du Bois, West Channels throughout the fieldwork period $\left(\mathrm{R}^{2}=\right.$ 0.95). The distribution of modelled water level variation was such that it was elevated at either end of the lagoon (Fig. 4D).
The cover of each benthic component predicted by the spatially lagged models closely corresponded to measurements made in the field $\left(\mathrm{R}^{2}\right.$ ranged between 0.79 and 0.88 ). In each case, the spatial distribution of the predicted benthic coverages inside the Aldabra lagoon showed a distinction between areas of the lagoon floor that were in close proximity to the channels and those at the centre of the lagoon (Fig. 5). One area of particular interest was the shallow platform in the northwest quadrant of the lagoon (Fig. 5A), formed by the erosive action of tidally driven currents, which typically reach $3 \mathrm{~m} \mathrm{~s}^{-1}$ on peak ebb tides (Stoddart et al. 1971). For both the ordinary least-squares and the spatially lagged models, the predicted distribution of live coral was elevated here, where numerous shallow coral patches were observed in the field (see also Stoddart et al. 1971, Price 1971, Taylor 1978, Potts \& Whitton 1980). Very little live coral was predicted to occur in the

\section{Model output}

In terms of the distribution of live coral, the ordinary least-squares and spatially lagged regression models explained 25 and $79 \%$ of the variation of validation points inside the lagoon, respectively. For both models, depth was negatively correlated and water level variation was positively correlated with the amount of live coral cover. The residuals from the ordinary least-squares regression model displayed strong positive spatial structure, which was corroborated by Moran's I (Fig. 5B). For the spatially lagged model, weak negative autocorrelation was apparent (Moran's I ranged from -0.14 to 0.21 ; Table 3 ).

For the remaining benthic coverages, the spatially lagged autoregressive models consistently performed better than the classic ordinary least-squares regression, explaining $81 \%$ (carbonate sand), $79 \%$ (dead coral) and $72 \%$ (macroalgae) of the variation in these components. The independent validation exercise indicated that the spatially lagged models performed well as benthic cover predictors with the following accuracies: live coral $\left(\mathrm{R}^{2}=0.88\right)$, carbonate sand $\left(R^{2}=0.86\right)$, macroalgae $\left(R^{2}=\right.$ $0.79)$ and dead coral $\left(\mathrm{R}^{2}=0.84\right)$. Water level variation had the highest $t$-statistic in all cases, apart from that of dead coral cover.

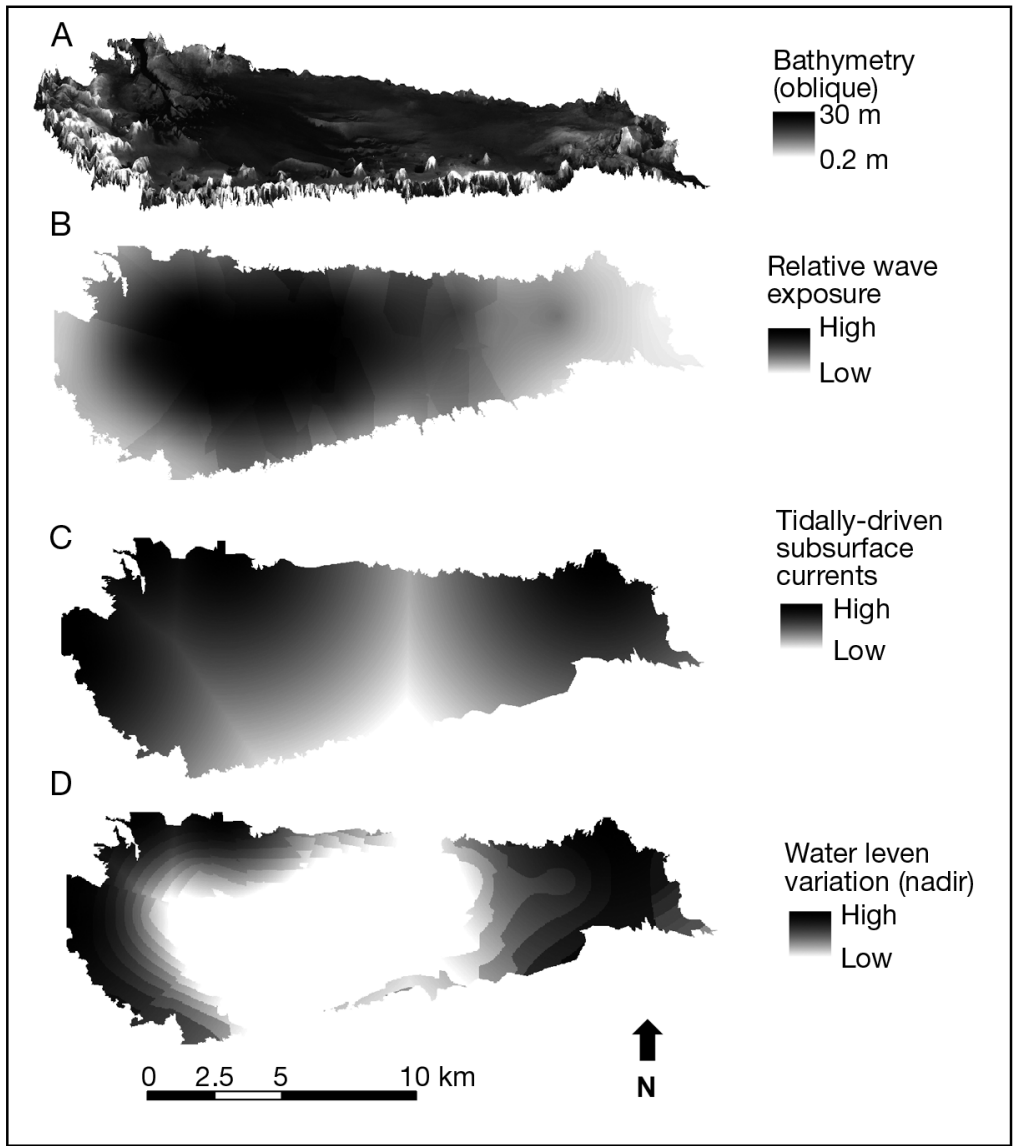

Fig. 4. The modelled independent variables (A) lagoon water depth $\left(X_{1}\right.$, Eq. 1), viewed from an oblique angle to emphasise vertical complexity; (B) relative wave exposure; (C) tidally driven subsurface currents; and (D) water level variation $\left(X_{2}\right.$, Eq. 2$)$, viewed from nadir to emphasise spatial variation across the lagoon 


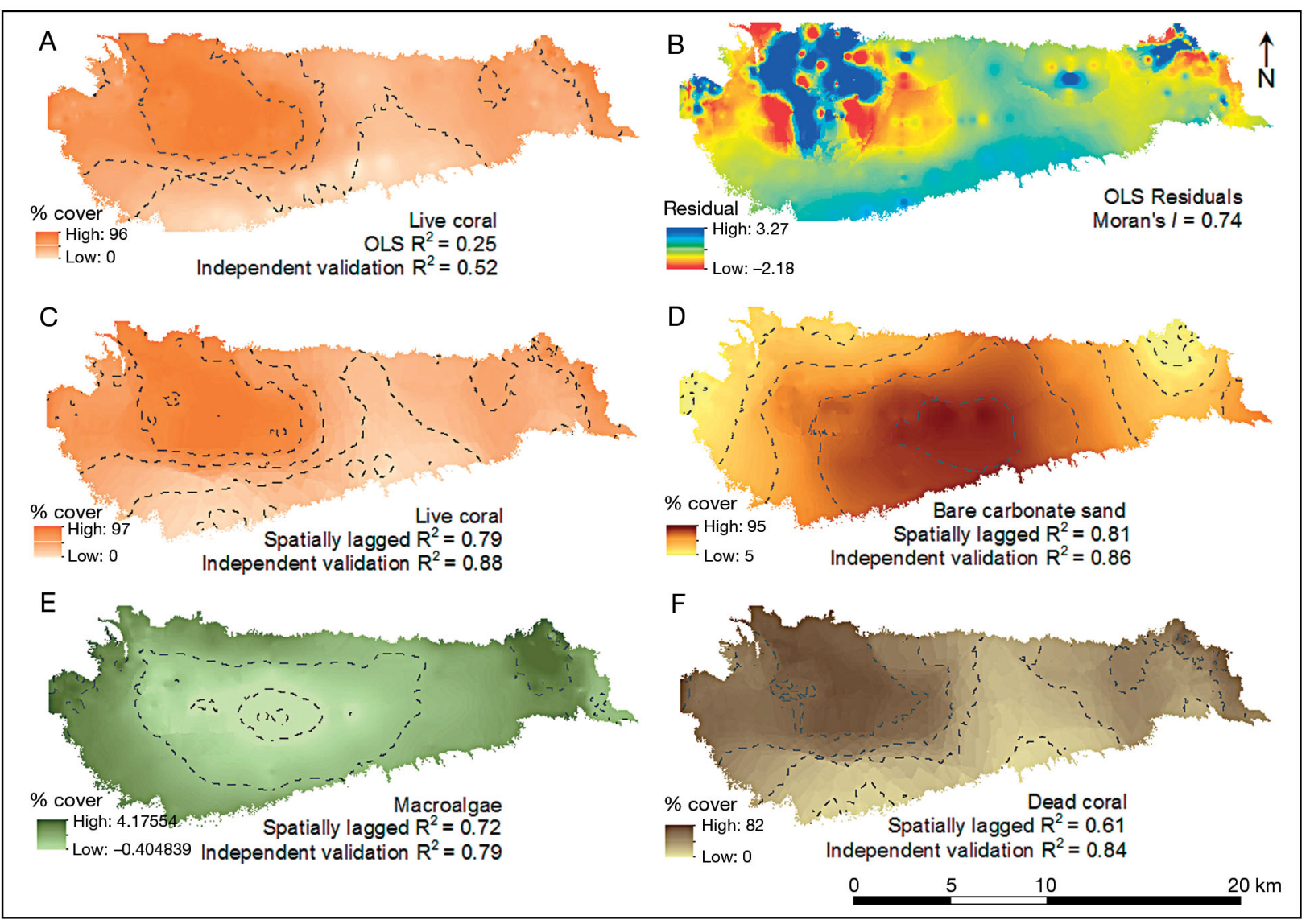

Fig. 5. Model output for the different lagoon benthic coverages; keys indicate percent cover modelled (Eqs. 2-4). (A) Predicted benthic cover of live coral generated from the ordinary least-squares (OLS) regression. (B) Standard deviation of Moran's I calculated for the residuals from the OLS regression model. $(\mathrm{C}-\mathrm{F})$ Predicted distributions for each of the benthic cover components generated from the spatially lagged autoregressive model: (C) live coral cover, (D) bare carbonate sand cover, (E) macroalgal cover and $(\mathrm{F})$ dead coral cover. Contours were generated for values equivalent to 1, 2 and 3 standard deviations from the mean value for each benthic cover component

south of the lagoon inside the enclosed atoll rim and in the lagoon centre.

The residuals of the ordinary least-squares model were spatially structured, with positively autocorrelated residuals occurring in association with Grande Passe and the secondary west and east channel openings (Moran's $I=0.74$, see blue patches in Fig. 5B). The predicted distribution of carbonate sand was high in the central section of the lagoon and lower around the channel openings at both the east and west margins of the lagoon. Within the central section, sand coverage was highest in the centre of the lagoon. The distribution of macroalgal cover was at its highest inside the channels at the eastern and western margins of the lagoon. Finally, dead coral and rubble were predicted to occur largely in association with live coral, both on the shallow platform to the northeast of the West Channels, and in association with Grande Passe and Passe Houareau (to the east).

\section{DISCUSSION}

Taylor (1978) related distinct associations of the molluscan and coral fauna at Aldabra to local sediment characteristics, which themselves reflect variability in hydrodynamic conditions. Inside the lagoon, these were broadly characterised as a 'Porites coral knoll' assemblage in the northwest and a 'Halimeda sand' assemblage in the east, with the complexity of hydrodynamic processes around the channels represented by a mosaic of sand, algal and coral habitats. For the western seaward reefs, Price (1971) noted the physiographic response of reef substrate and intertidal vegetation communities to wave action and water depth whereas the blue-green algae communities, occupying approximately $19 \%$ of the intertidal lagoon area, have been thought to be controlled by biotic processes, including competition and grazing (Potts \& Whitton 1980). The present study extends these previ- 
Table 3. Summary of results and diagnostics for each benthic cover class

\begin{tabular}{|c|c|}
\hline Diagnostic & Result \\
\hline \multicolumn{2}{|l|}{ Live coral: classic ordinary least-squares regression } \\
\hline $\mathrm{R}^{2}$ (adjusted value) & $0.25(0.26)$ \\
\hline $\mathrm{R}^{2}$ (validation accuracy) & 0.52 \\
\hline Moran's $I$ & 0.74 \\
\hline Water depth $\beta$ coefficient & -0.08 \\
\hline Water depth $t$-statistic & $-0.02(p<0.0002)$ \\
\hline Water level variation $\beta$ coefficient & 0.06 \\
\hline Water level variation $t$-statistic (probability at $2 \mathrm{df}$ ) & $0.03(\mathrm{p}<0.0003)$ \\
\hline \multicolumn{2}{|l|}{ Live coral: spatially lagged autoregressive model } \\
\hline $\mathrm{R}^{2}$ (adjusted value) & 0.79 \\
\hline $\mathrm{R}^{2}$ (validation accuracy) & 0.88 \\
\hline Moran's I & -0.12 \\
\hline Water depth $\beta$ coefficient (SE) & -0.132 \\
\hline Water depth $t$-statistic & $4.14(\mathrm{p}<0.001)$ \\
\hline Water level variation $\beta$ coefficient (SE) & 0.381 \\
\hline Water level variation $t$-statistic (probability at $2 \mathrm{df}$ ) & $8.80(\mathrm{p}<0.001)$ \\
\hline \multicolumn{2}{|l|}{ Carbonate sand: spatially lagged autoregressive model } \\
\hline $\mathrm{R}^{2}$ (adjusted value) & 0.81 \\
\hline $\mathrm{R}^{2}$ (validation accuracy) & 0.86 \\
\hline Moran's I & 0.21 \\
\hline Water depth $\beta$ coefficient (SE) & $0.021(0.029)$ \\
\hline Water depth $t$-statistic & $14.74(\mathrm{p}<0.001)$ \\
\hline Water level variation $\beta$ coefficient (SE) & $0.248(0.091)$ \\
\hline Water level variation $t$-statistic (probability at $2 \mathrm{df}$ ) & $27.78(\mathrm{p}<0.001)$ \\
\hline \multicolumn{2}{|l|}{ Macroalgae: spatially lagged autoregressive model } \\
\hline $\mathrm{R}^{2}$ (adjusted value) & 0.72 \\
\hline $\mathrm{R}^{2}$ (validation accuracy) & 0.79 \\
\hline Moran's I & 0.09 \\
\hline Water depth $\beta$ coefficient (SE) & $0.054(0.014)$ \\
\hline Water depth $t$-statistic & $13.31(\mathrm{p}<0.001)$ \\
\hline Water level variation $\beta$ coefficient (SE) & $0.377(0.112)$ \\
\hline Water level variation $t$-statistic (probability at $2 \mathrm{df}$ ) & $21.13(\mathrm{p}<0.001)$ \\
\hline \multicolumn{2}{|l|}{ Dead coral: spatially lagged autoregressive model } \\
\hline $\mathrm{R}^{2}$ (adjusted value) & 0.61 \\
\hline $\mathrm{R}^{2}$ (validation accuracy) & 0.84 \\
\hline Moran's $I$ & -0.14 \\
\hline Water depth $\beta$ coefficient (SE) & $0.145(0.111)$ \\
\hline Water depth $t$-statistic & $12.82(\mathrm{p}<0.001)$ \\
\hline Water level variation $\beta$ coefficient (SE) & $0.213(0.073)$ \\
\hline Water level variation $t$-statistic (probability at $2 \mathrm{df}$ ) & $8.04(\mathrm{p}<0.001)$ \\
\hline
\end{tabular}

provides a favourable environment for a shallow reticulated network of branching acroporid corals along the northern flank of Grande Passe. It has been suggested for other atoll lagoons (e.g. Tuamotu archipelago, SW Pacific Ocean; Houtman Abrolhos, western Australia; and Kiribati, Central Pacific Ocean), that reticulate and cellular reef development results from self-organisation in coral reefs, and is an emergent property of the morphodynamic linkages between rapid lagoonal reef growth and tidally and wave-driven water circulation patterns (Blanchon 2011). This is supported by the video evidence collected in the present study as the northwestern lagoon quadrant shows a greater degree of reef development than that seen in the east, which relates to smaller, discrete patches of coral. The predicted distribution of dead coral inside the lagoon closely resembles that of live coral, suggesting limited movement of rubble across the shallow sandflat above Grande Passe.

The $t$-test values suggest that both water depth and circulation are significant predictors of benthic cover $(p<0.001)$ and it follows that their contributions to the overall lagoon benthic cover models are valuable. For the spatially lagged models, $\mathrm{R}^{2}$ values ranged from 0.61 to 0.81 . This may be because of the presence of benthic community components that are reliant on photosynthetic activity, such as coral and algae, for which light interception is closely coupled

ous observations by generating predictions of the spatially continuous coverage of 4 benthic components (live coral, bare carbonate sand, macroalgae and dead coral) for the whole lagoon. It can be seen from the results of the spatially lagged live coral cover model that the development of live coral stands inside Aldabra Atoll lagoon is highly localised, with the northwestern quadrant emerging as a key site for live coral development on top of a shallow carbonate sandflat (coral coverage ranging from 40 to $60 \%$ ). This distribution may be due to enhanced wave exposure in this section of the lagoon (Fig. 5B), which clearly favours the Porites knoll communities but also particularly with water depth (Finelli et al. 2006). Furthermore, within the highly enclosed and topographically variable lagoon at Aldabra, tidal fluctuations and ponding effects result in the uneven insolation of shallow platforms. Superimposed on these depth controls, as in other atoll lagoons (Kraines et al. 2001), it is likely that water flow driven by wave stress and tidal currents controls the availability and diffusion rate of nutrients and oceanic plankton biomass to, as well the flushing of particulate matter from, benthic communities inside the Aldabra lagoon.

The application of a spatially explicit modelling methodology to the Aldabra lagoon, in which a clear 
association was maintained and exploited between ground referencing points and the spatial coordinates that located them, enabled autocorrelation of the lagoon benthic assemblages (a widely held property of ecological data sets) to be addressed in a statistically rigorous manner. The initial ordinary leastsquares model displayed spatial dependence, which may have inflated the goodness-of-fit measure and underestimated the $\mathrm{SE}$, increasing the likelihood of a Type I error. Because of this departure from the true independence of observations and failure to include spatial autocorrelation in the specification, some of the effect due to interaction would likely have been allocated to the existing covariates, particularly those with a similar spatial structure to the response variable. Incorporation of a neighbourhood context effect operating through a spatially lagged expression of the response variable allowed this to be addressed. Such a step avoids some of the statistical pitfalls associated with other methods that apply classic regression analysis to generate spatially continuous predictions of benthic character on coral reefs (Garza-Pérez et al. 2004, McClanahan \& Karnauskas 2011).

The spatially lagged autoregressive term incorporated information into the model on the response variable itself at sites adjacent to each data point. Any resulting change in predictive power of the model is instructive on the nature (exogenous versus endogenous) of controls on benthic cover (Cliff \& Ord 1981). It follows, therefore, that because the power of the models was enhanced through the introduction of an autoregressive term, this was attributable to the influence of an endogenous effect acting through a neighbourhood context. Ecological processes underpinning such an effect in an atoll lagoon may include competition for light, larval dispersal and water residence times. Spatially explicit biotic-abiotic relationships inside atoll lagoons such as those empirically defined by the present study can be further tested as predictors of the distribution of macrofaunal lagoon benthic assemblages elsewhere in the Indo-Pacific biogeographic region. In particular, the application of these models may yield insight into the nature of species-environment relationships and potential additional environmental parameters of relevance to lagoons characterised by a different size, shape or water depth. Such an approach applies to the common data scenario for coral reef sites where full coverage information is available on physical variables such as water depth and water level variation, accompanied by point samples of biological communities where field visits were possible.

\section{CONCLUSIONS}

This analysis adds a spatially explicit and statistically rigorous approach to the growing body of bottom-up models used for upscaling local field data to spatially continuous landscapes in an ecologically meaningful manner. Applied for the first time in an atoll lagoon, the species-environment linkages revealed are relevant to similar modelling activities both regionally and globally. In this case, transition to a model that incorporated spatial dependence was accompanied by a marked growth in predictive power (in the example of live coral, $\mathrm{R}^{2}$ increased from a value of 0.25 to 0.79 ). The theoretical implication that follows is that neighbourhood interactions play an important role in defining the benthic character of lagoon floors. This invites greater consideration of interaction between sites, providing a persuasive case for explicitly building geographical considerations into ecological studies of benthic cover classes inside atoll lagoons. Finally, the application of such techniques has value for focusing conservation and resource management activities, both in a geographical and a thematic sense. For example, the output is expressed on a ratio scale, which represents a high measurement level that can be utilised (through contouring or the application of thresholds) to identify a set of representative locations in line with established conservation objectives (Roberts et al. 2003).

Acknowledgements. This work would not have been possible without the generous support of the Seychelles Islands Foundation, in particular through the work of Dr Frauke Fleischer-Dogley. Additional funding was obtained from the Seychelles Environment Trust and the Cambridge Coastal Research Unit, Department of Geography, University of Cambridge. We are grateful to Robyn James, University of Queensland, and especially Lilian Pintea, Director of Conservation Science, Jane Goodall Institute, for the acquisition of Quickbird imagery. Captain Joshua Adeline is thanked for assistance with fieldwork.

\section{LITERATURE CITED}

Adjeroud M, Andréfouët S, Payri C (2001) Mass mortality of macrobenthic communities in the lagoon of Hikeru atoll (French Polynesia). Coral Reefs 19:287-291

> Almany GR, Connolly SR, Heath DD, Hogan JD and others (2009) Connectivity, biodiversity conservation and the design of marine reserve networks for coral reefs. Coral Reefs 28:339-351

> Andréfouët S, Pages J, Tartinville B (2001) Water renewal time for classification of atoll lagoons in the Tuamotu Archipelago (French Polynesia). Coral Reefs 20:399-408

Andréfouët S, Chagnaud N, Kranenburg C (2009) Atlas of western and central Indian Ocean coral reefs. Centre IRD de Nouméa, Nouméa, Nouvelle-Calédonie 
Anselin L, Bera A (1998) Spatial dependence in linear regression models with an introduction to spatial econometrics. In: Ullah A, Giles DE (eds) Handbook of applied economic statistics. Marcel Dekker Press, New York, NY p 237-289

Arias-Gonzalez JE, Acosta-Gonzalez G, Membrillo M, Garza-Perez JR, Castro-Perez JM (2011) Predicting spatially explicit coral reef fish abundance, richness and Shannon-Weaver index from habitat characteristics. Biodivers Conserv 21:115-130

Beale CM, Lennon JJ, Yearsley JL, Brewer MJ, Elston DA (2010) Regression analysis of spatial data. Ecol Lett 13: 246-264

Blanchon P (2011) Geomorphic zonation. In: Hopley D (ed) Encyclopedia of modern coral reefs: structure, form and process. Springer-Verlag, Berlin, p. 469-496

> Charpy L, Roubaud-Charpy CJ (1990) A model of the relationship between light and primary production in an atoll lagoon. J Mar Biol Assoc UK 70:357-369

Cliff AD, Ord JK (1981) Spatial processes: models and applications. Pion, London

Delesalle B, Sournia A (1992) Residence time of water and phytoplankton biomass in coral reef lagoons. Cont Shelf Res 12:939-949

Done TJ (2011) Corals: environmental controls on growth. In: Hopley D (ed) Encyclopedia of modern coral reefs: structure, form and process. Springer-Verlag, Berlin, p 281-293

Dray S, Pélissier R, Cputeron P, Fortin MJ and others (2012) Community ecology in the age of multivariate multiscale spatial analysis. Ecol Monogr (in press) doi:10.1890/111183.1

Dufour P, Harmelin-Vivien M (1997) A research programme for a typology of atoll lagoons: strategy and first results. Proc 8th Int Coral Reef Symp 1:843-848

Farrow GE (1971) Back-reef and lagoonal environments of Aldabra Atoll, distinguished by their crustacean burrows. Symp Zool Soc Lond 28:455-500

Farrow GE, Brander KM (1971) Tidal studies on Aldabra. Philos Trans R Soc Lond B 260:93-121

- Finelli CM, Helmuch BS, Pentcheff ND, Wethey DS (2006) Water flow influences oxygen transport and photosynthetic efficiency in corals. Coral Reefs 25:47-57

Garza-Pérez JR, Lehmann A, Arias-González JE (2004) Spatial prediction of coral reef habitats: integrating ecology with spatial modeling and remote sensing. Mar Ecol Prog Ser 269:141-152

Haining RH (2003) Spatial data analysis: theory and practice. Cambridge University Press, Cambridge

- Harborne AR, Mumby PJ, ychaluk K, Hedley JD, Blackwell PG (2006) Modeling the beta diversity of coral reefs. Ecology 87:2871-2881

Hillary A, Kokkonen M, Max L (2002) Proceedings of the World Heritage Marine Biodiversity Workshop. World Heritage Papers 4, UNESCO World Heritage Centre, Paris

Jenness J (2006) Radiating lines and points (rad_lines.avx) extension for ArcView 3.x, v. 1.1. Jenness Enterprises, Flagstaff, AZ, available at www.jennessent.com/ arcview/radiating_lines.htm

Karpouzli E, Malthus T (2003) The empirical line method for the atmospheric correction of IKONOS imagery. Int $\mathrm{J}$ Remote Sens 24:1143-1150

Kohler KE, Gill SM (2006) Coral point count with Excel extensions (CPCe): a Visual Basic program for the deter- mination of coral and substrate coverage using random point count methodology. Comput Geosci 32:1259-1269

Kraines SB, Isobe M, Komiyama H (2001) Seasonal variations in the exchange of water and water-borne particles at Majuro Atoll, the Republic of the Marshall Islands. Coral Reefs 20:330-340

> Langmead O, Sheppard C (2004) Coral reef community dynamics and disturbance: a simulation model. Ecol Model 175:271-290

> Leclerc AM, Baptiste P, Texier D, Broc D (1999) Density induced water circulation in atoll coral reefs: a numerical study. Limnol Oceanogr 44:1268-1281

- Lehmann A, Overton JM, Leathwick JR (2003) GRASP: generalized regression analysis and spatial prediction. Ecol Model 160:165-183

Leis JM (1994) Coral sea atoll lagoons: closed nurseries for the larvae of a few coral reef fishes. Bull Mar Sci 54: 206-227

Lichstein JW, Simons TR, Shriner SA, Franzreb KE (2002) Spatial autocorrelation and autoregressive models in ecology. Ecol Monogr 72:445-463

Macnae W (1971) Mangroves on Aldabra. Philos Trans R Soc Lond B 260:237-247

McClanahan T, Karnauskas M (2011) Relationships between benthic cover, current strength, herbivory, and a fisheries closure in Glovers Reef Atoll, Belize. Coral Reefs 30:9-19

> Mellin C, Andréfouët S, Ponton D (2007) Spatial predictability of juvenile fish species richness and abundance in a coral reef environment. Coral Reefs 26:895-907

- Mellin C, Bradshaw C, Meekan MG, Caley MJ (2010) Environmental and spatial predictors of species richness and abundance in coral reef fishes. Glob Ecol Biogeogr 19: 212-222

> Mellin C, Delean S, Caley J, Edgar G, Meekan M (2011) Effectiveness of biological surrogates for predicting patterns of marine biodiversity: a global meta-analysis. PLoS ONE 6:e20141

Menard HW (1982) Influence of rainfall upon the morphology and distribution of atolls. In: Scrutton RA, Talwani M (eds) The ocean floor. John Wiley \& Sons, New York, NY p 305-311

> Pages J, Andréfouët S (2001) A reconnaissance approach for hydrology of atoll lagoons. Coral Reefs 20:409-414

Pepper AP, Puotinen ML (2009) GREMO: A GIS-based generic model for estimating relative wave exposure. 18th World Interface Modelling and Simulation Congress, Cairns p 1964-1970

Pittman SJ, Brown KA (2011) Multi-scale approach for predicting fish species distributions across coral reef seascapes. PLoS ONE 6:e20583

Pittman SJ, Costa BM, Battista TA (2009) Using lidar bathymetry and boosted regression trees to predict the diversity and abundance of fish and corals. J Coast Res 53:27-38

Potts M, Whitton BA (1980) Vegetation of the intertidal zone of the lagoon of Aldabra, with particular reference to the photosynthetic prokaryotic communities. Philos Trans R Soc Lond B 208:13-55

> Price JH (1971) The shallow sublittoral marine ecology of Aldabra. Philos Trans R Soc Lond B 260:123-171

Pugh DT (1979) Sea levels at Aldabra Atoll, Mombasa and Mahe, western equatorial Indian Ocean, related to tides, meteorology and ocean circulation. Deep-Sea Res 26: $237-258$ 
Pugh DT, Rayner RF (1981) The tidal regimes of three Indian Ocean atolls and some ecological implications. Estuar Coast Shelf Sci 13:389-407

Purdy EG (1974) Reef configurations: cause and effect. In: Laporte LF (ed) Reefs in time and space. Soc Econ Paleontol Mineral Spec Publ 18:9-76

Purkis S, Graham N, Riegl B (2008) Predictability of reef fish diversity and abundance using remote sensing data in Diego Garcia (Chagos Archipelago). Coral Reefs 27: 167-178

Roberts C, Andelman S, Branch GR, Bustamante JC and others (2003) Ecological criteria for evaluating candidate sites for marine reserves. Ecol Appl 13:199-214

Schott F, McCreary JP (2001) The monsoon circulation of the Indian Ocean. Prog Oceanogr 51:1-123

Shumchenia EJ, King JW (2010) Comparison of methods for integrating biological and physical data for marine habitat mapping and classification. Cont Shelf Res 30: 1717-1729

Shepard FP (1970) Lagoonal topography of Caroline and Marshall Islands. Geol Soc Am Bull 81:1905-1914

Smirnov O, Anselin L (2001) Fast maximum likelihood estimation of very large spatial autoregressive models: a characteristic polynomial approach. Comput Stat Data Anal 35:301-319

Sobel J, Dahlgren C (2004) Marine reserves: a guide to sci-

Editorial responsibility: Charles Birkeland,

Honolulu, Hawaii, USA ence, design and use. Island Press, Washington, DC

Stevens T (2005) Scales of similarity in soft sediment epibenthic assemblages: implications for marine protected area design. Mar Biol 146:345-354

Stoddart DR (1968) The conservation of Aldabra. Geogr J 134:471-485

Stoddart DR (1984) Biogeography and ecology of the Seychelles Islands. Dr W. Junk Publishers, The Hague

Stoddart DR, Taylor JD, Fosberg FR (1971) Geomorphology of Aldabra Atoll. Philos Trans R Soc Lond B 260:31-65

Stumpf RP, Holderied K, Sinclair M (2003) Determination of water depth with high-resolution satellite imagery over variable bottom types. Limnol Oceanogr 48:547-556

Taylor JD (1971) Intertidal zonation at Aldabra Atoll. Philos Trans R Soc Lond B 260:173-213

Taylor JD (1978) Faunal response to the instability of reef habitats: Pleistocene molluscan assemblages of Aldabra Atoll. Palaeontology 21:1-30

Tobler W (1970) A computer movie simulating urban growth in the Detroit region. Econ Geogr 46:234-240

Tolman HL (2002) User manual and system documentation of WAVEWATCH-III version 2.22. NOAA/NWS/NCEP/ MMAB, available at http://polar.ncep.noaa.gov/waves/ wavewatch/

Wiens HJ (1962) Atoll environment and ecology. Yale University Press, New Haven, CT

Submitted: January 12, 2012; Accepted: April 23, 2012

Proofs received from author(s): July 5, 2012 